\title{
Balanced crystalloids versus isotonic saline in critically ill patients: systematic review and meta-analysis
}

\author{
Yazan Z. M. Zayed ${ }^{1,3^{*}}$ D, Ahmed M. Y. Aburahma' ${ }^{1}$, Mahmoud O. Barbarawi ${ }^{1}$, Kewan Hamid', \\ Momen R. N. Banifadel ${ }^{2}$, Laith Rashdan ${ }^{1}$ and Ghassan I. Bachuwa ${ }^{1}$
}

\begin{abstract}
Objectives: Intravenous fluids are one of the most used medical therapy for patients, especially critically ill patients. We conducted a meta-analysis comparing between balanced crystalloids and normal saline in critically ill patients and its effect on various clinical outcomes.

Design: Meta-analysis and systematic review of randomized clinical trials (RCTs).

Methods and data source: Electronic search was performed using PubMed, Cochrane library, and clinical trials. gov from inception through March 1, 2018, with inclusion of prospective studies that investigated one of the primary outcomes which were acute kidney injury (AKI) and in-hospital mortality while secondary outcomes were intensive care unit (ICU) mortality and new renal replacement therapy (RRT).

Results: Six RCTs were included. Total of 19,332 patients were included in the final analysis. There was no significant difference in in-hospital mortality (11.5\% vs 12.2\%; OR 0.92; 95\% Cl 0.85-1.01; $\left.P=0.09 ; P^{2}=0 \%\right)$, incidence of AKI (12\% vs 12.7\%, OR 0.92; 95\% Cl 0.84-1.01; $\left.P=0.1 ; P^{2}=0\right)$, overall ICU mortality (OR 0.9, 95\% Cl $0.81-1.01, P=0.08, P^{2}=0 \%$ ), or need for new RRT (OR 0.92, 95\% Cl 0.67-1.28, $P=0.65, P=38 \%$ ) between balanced crystalloids and isotonic saline in critically ill patients.
\end{abstract}

Conclusion: Balanced crystalloids and isotonic saline have no difference on various clinical outcomes including in-hospital mortality, AKI, overall ICU mortality, and new RRT. Further powerful clinical trials are required to determine the relationship between crystalloid fluid type and clinical outcomes.

Keywords: Balanced crystalloids, Isotonic saline, Critically ill patients, Fluid therapy and meta-analysis

\section{Background}

Intravenous fluids are one of the most commonly used medical therapies for patients especially in intensive care units (ICUs). Isotonic saline has been the most commonly used crystalloid for fluid resuscitation $[1,2]$.

The balanced crystalloids like lactated Ringer's and Plasma-Lyte solutions have an electrolyte composition which is closer to plasma. Balanced crystalloids are increasingly used for resuscitation of patients

\footnotetext{
* Correspondence: yz.alzayed@yahoo.com; yzayed1@hurleymc.com ${ }^{1}$ Internal Medicine Department, Hurley Medical Center/Michigan State University College of Human Medicine, Flint, MI, USA

${ }^{3}$ East Lansing, USA

Full list of author information is available at the end of the article
}

undergoing surgery, trauma, and diabetic ketoacidosis especially with data suggesting that the use of isotonic normal saline is associated with increased risk of acute kidney injury (AKI) and hyperchloremic metabolic acidosis [3-8]. On the other hand, some of the balanced solutions are considered hypotonic given the lower sodium concentrations and are associated with metabolic alkalosis, hyperlactemia, and hypotonicity especially when administered in large volumes [2].

Many studies have investigated the effect of crystalloid fluid type given for patients and adverse outcomes. In a prospective study in critically ill patients, chloride-restrictive fluid strategy was associated with decreased incidence of AKI and need for new renal replacement therapy (RRT) when compared to rich

(C) The Author(s). 2018 Open Access This article is distributed under the terms of the Creative Commons Attribution 4.0 International License (http://creativecommons.org/licenses/by/4.0/), which permits unrestricted use, distribution, and 
chloride fluids [3]. In addition, resuscitation with Plasma-Lyte solution at the day of surgery was associated with a decrease in rate of major complications including new RRT, incidence of infections, and blood transfusion in comparison to isotonic saline in a retrospective matched observational study [8].

Other prospective and observational studies have controversial findings as some studies showed that balanced solutions are associated with decreased rate of AKI, new RRT, and death $[3,5,8,9]$, while other studies found no difference in these outcomes between both strategies $[10,11]$.

A recent meta-analysis concluded that balanced fluids are more beneficial than isotonic saline in keeping postoperative electrolytes and acid-base balance among adult patients undergoing non-renal surgery [12]. On the other hand, a meta-analysis comparing between balanced and isotonic saline in operation rooms and ICUs showed no difference in AKI neither in-hospital mortality between the two fluid types [13].

In front of this conflict, we are performing a metaanalysis that involved all prospective trials comparing between balanced crystalloids and normal saline fluid resuscitation exclusively in critically ill patients. Balanced fluids include lactated Ringer's, Hartmann's solution, or Plasma-Lyte solutions while isotonic fluids pointed toward use of normal saline.

\section{Methodology}

\section{Literature search and data source}

We conducted our meta-analysis according to the Preferred Reporting Items for Systematic Reviews and Meta-Analyses Protocols (PRISMA-P) Statement 2015 [14]. An electronic literature search was performed independently and separately by three investigators (A.A., M. B., and Y.Z) in accordance with the recommendations of the Cochrane Collaboration, using PubMed, ClinicalTrials.gov, and Cochrane library from inception through March 01, 2018. Any disagreement was solved by a discussion of three reviewers and a fourth investigator (M.Ba.). Neither language nor demographic restrictions were applied. As well, references of the relevant studies and meta-analyses were reviewed for possible eligibility.

Studies were first screened by titles and abstracts for eligibility. The full texts of eligible studies were reviewed in the second step before exclusion. The search process is detailed in Fig. 1. The electronic search was archived through Mendeley program and is available on request.

\section{Study selection}

We have included randomized clinical trials (RCTs) comparing between balanced crystalloids and isotonic saline in critically ill adult patients who received their management in ICUs. Studies that provided at least

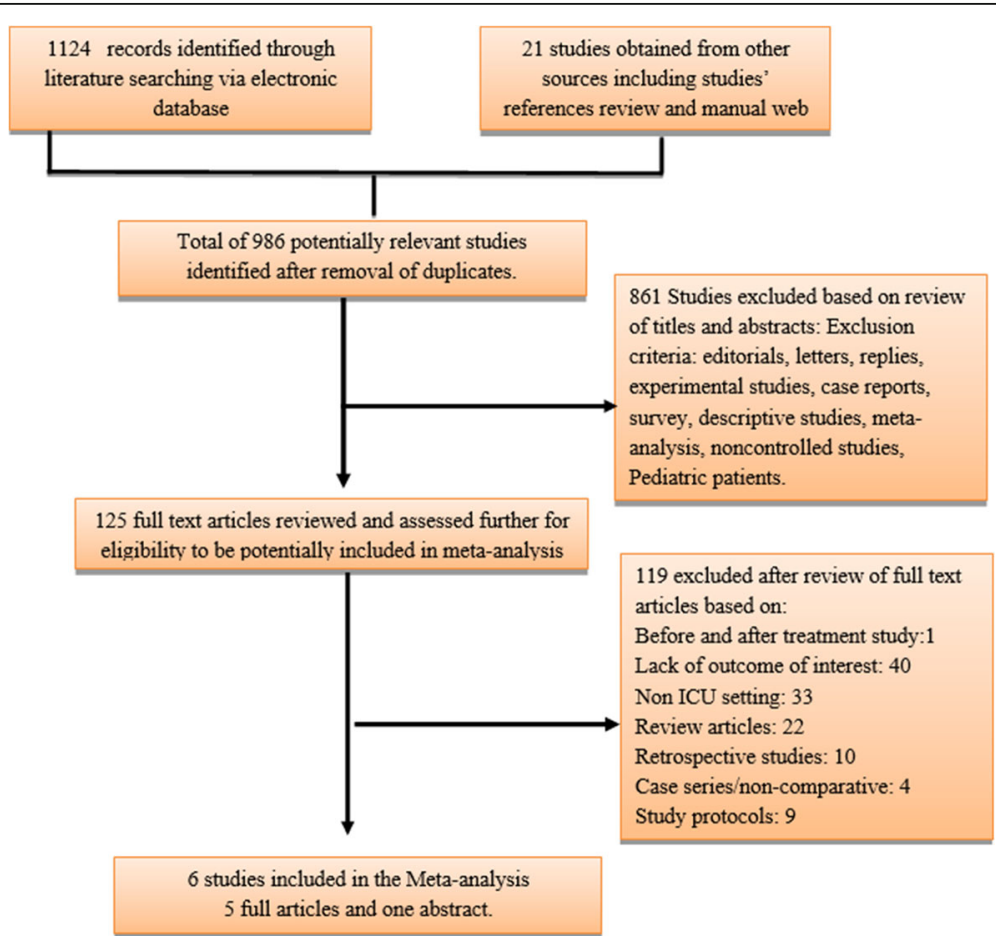

Fig. 1 Flow diagram of literature search and study selection based on Preferred Reporting Items for Systematic Reviews and Meta-Analyses Protocols (PRISMA-P) recommendation 
one of our primary endpoints which are in-hospital mortality and incidence of AKI were included. Retrospective studies and before andafter treatment studies were excluded to decrease bias and confounding variables. Of the prospective studies, we excluded all studies that investigated the effect of crystalloid fluid type given in non-ICU setting like emergency department or intra-operative rooms or given to non-critically ill patients.

We performed quality assessment for the included RCTs for which we have full articles based on Cochrane collaboration's tool for assessing risk of bias in RCTs. We assessed included RCTs for random sequence generation, allocation concealment, blinding of participant and personnel, blinding of outcome assessment, incomplete outcome data, selective reporting, and other biases. We classified studies as low risk for bias only if all the described items were adequately described as low risk. Quality assessment results are shown in Fig. 2.

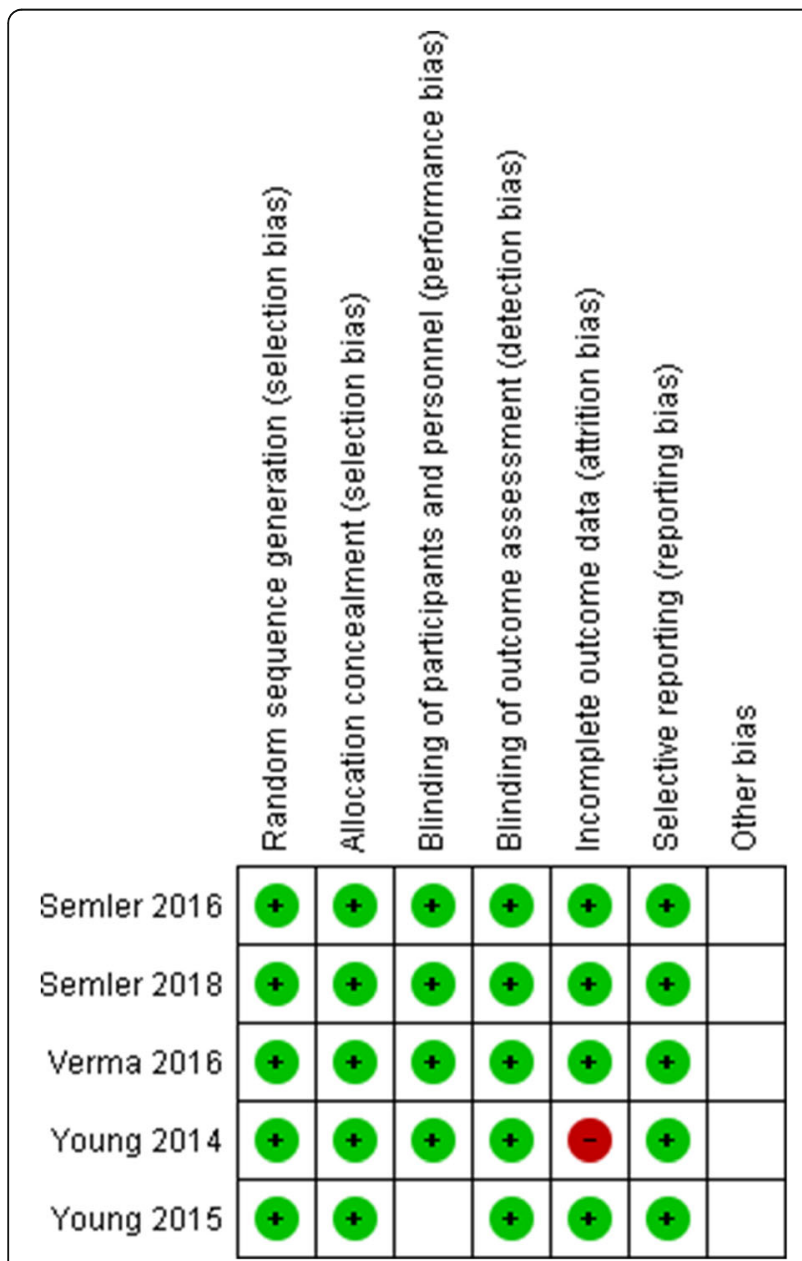

Fig. 2 Risk of bias summary: review author's judgments about each risk of bias item for each included study except Ratanarat et al.'s study

\section{Data extraction}

Three reviewers (A.A, M. B, Y.Z.) independently and separately extracted the data into a predesigned form from the included studies. Any disagreement was solved by a discussion between the three reviewers and fourth investigator (M.Ba.).

\section{Outcomes}

The primary outcome measures are AKI and in-hospital mortality at the longest follow-up provided by the study for either outcome measures. Patient who developed stage 2 or higher based on KDIGO (Kidney Disease Improving Global Outcome) criteria or injury or higher based on RIFLE (Risk, Injury, Failure, Loss, End stage) criteria were included in for analysis of AKI. This was chosen to make the measurement of AKI outcome similar between studies which used either of those two cut-off points. As well, it represents moderate to severe kidney injury. In-hospital mortality is defined as mortality before discharge or at the longest follow-up period provided by the study.

Secondary outcomes were needed for new RRT and ICU mortality.

\section{Statistical analysis}

Statistical analysis was performed using the comprehensive meta-analysis program. Statistics were pooled using random effect model; odds ratios (OR) for binary outcomes, with $95 \%$ confidence intervals $(95 \% \mathrm{CI}$ ) were calculated. We measured two-sided $P$ values for each outcome and statistical significance was determined by a two-tailed $P$ value $<0.05$. Heterogeneity among studies is reported using the $I^{2}, Q$ value statistic, and was gathered using random effect model for dichotomous co-variables. Since no enough data provided by the included studies about the outcomes in specific clinical situation like septic shock or surgical patients, sensitivity analysis could not be done.

\section{Results}

Search process and summary of included studies

A through literature search has resulted in 1124 articles from electronic searches and 21 articles from other sources including manual web search and references review of relevant studies and meta-analyses.

We have included six RCTs that compared fluid therapy with balanced crystalloids vs isotonic saline in critically ill patients [10,11,15-18]. Table 1 explains the summary of included studies and Fig. 1 showed the information relevant to the search process. Forty studies were excluded due to lack of outcome of interest as most of those studies were concerned about acid-base status change, effects on electrolytes, inflammatory markers, and fluid balance during first days after administration of intravenous fluids. 
Table 1 Summary of included studies

\begin{tabular}{|c|c|c|c|c|c|c|}
\hline First author & Year & Study design & Follow-up period for outcomes & Reported outcomes & Fluid type & $\begin{array}{l}\text { Number } \\
\text { of total } \\
\text { patients }\end{array}$ \\
\hline \multirow[t]{2}{*}{ Young } & \multirow[t]{2}{*}{2015} & \multirow{2}{*}{$\begin{array}{l}\text { Multi-center double-blind, } \\
\text { cluster randomized, } \\
\text { double-crossover trial }\end{array}$} & \multirow{2}{*}{$\begin{array}{l}90 \text { days after randomizations for } \\
\text { all variables }\end{array}$} & \multirow{2}{*}{$\begin{array}{l}\text { Hospital and ICU } \\
\text { mortality, AKI and } \\
\text { RRT }\end{array}$} & Plasma-Lyte & 1152 \\
\hline & & & & & Saline & 1110 \\
\hline \multirow[t]{2}{*}{ Verma } & \multirow[t]{2}{*}{2016} & \multirow{2}{*}{$\begin{array}{l}\text { Multi-center double-bind } \\
\text { randomized controlled trial }\end{array}$} & \multirow{2}{*}{$\begin{array}{l}\text { AKI during the first } 4 \text { days while } \\
\text { other outcomes till discharge }\end{array}$} & \multirow{2}{*}{$\begin{array}{l}\text { Hospital and ICU } \\
\text { mortality, AKI and } \\
\text { RRT }\end{array}$} & Plasma-Lyte & 33 \\
\hline & & & & & Saline & 34 \\
\hline \multirow{2}{*}{$\begin{array}{l}\text { Semler } \\
\text { (SMART trial) }\end{array}$} & \multirow[t]{2}{*}{2018} & \multirow{2}{*}{$\begin{array}{l}\text { Single center unblinded, } \\
\text { cluster randomized, } \\
\text { multiple crossover trial }\end{array}$} & \multirow{2}{*}{$\begin{array}{l}\text { Death at } 60 \text { days, AKI after } \\
\text { enrollment, RRT at } 28 \text { days. }\end{array}$} & \multirow{2}{*}{$\begin{array}{l}\text { Hospital and ICU } \\
\text { mortality, AKI and } \\
\text { RRT }\end{array}$} & LR or Plasma-Lyte & 7942 \\
\hline & & & & & Saline & 7860 \\
\hline \multirow{2}{*}{$\begin{array}{l}\text { Semler } \\
\text { (SALT trial) }\end{array}$} & \multirow[t]{2}{*}{2016} & \multirow{2}{*}{$\begin{array}{l}\text { Single-center prospective, } \\
\text { open-label, cluster-randomized, } \\
\text { multiple crossover trial }\end{array}$} & \multirow{2}{*}{$\begin{array}{l}\text { Death at } 60 \text { days, AKI after } \\
\text { enrollment, RRT at } 28 \text { days. }\end{array}$} & \multirow{2}{*}{$\begin{array}{l}\text { Hospital and ICU } \\
\text { mortality, AKI and } \\
\text { RRT }\end{array}$} & LR or Plasma-Lyte & 520 \\
\hline & & & & & Saline & 454 \\
\hline \multirow[t]{2}{*}{ Young } & \multirow[t]{2}{*}{2014} & \multirow{2}{*}{$\begin{array}{l}\text { Single center randomized, } \\
\text { double-blind, parallel-group } \\
\text { clinical trial }\end{array}$} & \multirow[t]{2}{*}{ In-hospital mortality at 30 days } & \multirow[t]{2}{*}{ Hospital mortality } & Plasma-Lyte & 22 \\
\hline & & & & & Saline & 24 \\
\hline \multirow[t]{2}{*}{ Ratanarat } & \multirow[t]{2}{*}{2017} & \multirow{2}{*}{$\begin{array}{l}\text { Single-center randomized } \\
\text { controlled trial }\end{array}$} & \multirow[t]{2}{*}{ AKI during the first 7 days } & \multirow[t]{2}{*}{ AKI and RRT } & Balanced & 88 \\
\hline & & & & & Saline & 93 \\
\hline
\end{tabular}

$A K I$ acute kidney injury, $R R T$ renal replacement therapy, $I C U$ intensive care unit, $L R$ lactated Ringer's

The total number of included patients in our review and meta-analysis is 19,332 patients, 9757 patients in balanced crystalloids group and 9575 patients in isotonic saline. A total of 19,151 patients were included in in-hospital mortality analysis and 18,337 patients were included in AKI and RRT analyses while ICU mortality analysis included 19,105 patients.

\section{Baseline characteristics of patients}

We included a total of 19,332 patients in both groups, and a total of 12,066 out of 19,151 were male (57.7\% in balanced fluids and $58.9 \%$ in isotonic saline). Sepsis and/or septic shock were diagnosed in 2709 out 19,151 (13.9\% in balanced fluids and $14.3 \%$ in isotonic saline). Of the patients, 6647 out of 19,151 were on mechanical ventilator $(38.1 \%$ in balanced fluid vs $31.2 \%$ in saline group).

Table 2 shows the demographic and baseline clinical characteristics of included study population.

\section{Outcome results}

\section{Primary outcomes}

The incidence of in-hospital mortality in both groups were similar ( $11.5 \%$ vs $12.2 \%$, OR 0.92 ; $95 \%$ CI $0.85-$ 1.01; $P=0.09 ; I^{2}=0 \%$ ) (Fig. 3).

As well, the difference in incidence of AKI was not statistically significant ( $12 \%$ versus $12.7 \%$, OR $0.92 ; 95 \%$ CI 0.84-1.01; $P=0.1 ; I^{2}=0 \%$ ) (Fig. 4).

\section{Secondary outcomes}

There was no significant difference between both groups of fluids in incidence of overall ICU mortality (OR 0.9, 95\% CI $0.81-1.01, P=0.08, I^{2}=0 \%$ ) or in need for new RRT (OR
$0.92,95 \%$ CI $0.67-1.28, P=0.65, I^{2}=38 \%$ ) (Additional file 1 : Figure S1 and Additional file 2: Figure S2).

\section{Discussion}

Our meta-analysis revealed the following key findings: there are no significant differences between balanced crystalloids and isotonic saline, in the incidence of in-hospital mortality, AKI, ICU mortality, or need for new RRT in critically ill patients.

The strength of our meta-analysis is that it involved more than 19,000 patients from six RCTs. Retrospective studies and before and after treatment studies were excluded to decrease the risk of bias and confounding variables, as well; we included only studies that involved critically ill patients who received their management in the ICU to measure the response of this group of patients.

In two previously published meta-analyses evaluating the difference between both fluid types in unselected patient's population involving surgical patients in perioperative period and kidney transplant in addition to critically ill patients, there was no difference in in-hospital mortality and incidence of AKI in both groups. Although both reviews have several limitations including the heterogeneity in patient's population, and small sample size and few studies evaluated only critically ill patients, their results were in concordance with the results of our meta-analysis which was conducted exclusively in critically ill patients $[13,19]$.

A recently published randomized controlled trial (SMART study) involving about 15,000 patients concluded that balanced crystalloids have a decreased incidence of the primary outcome, major adverse kidney events defined 
Table 2 Baseline characteristics of study population

\begin{tabular}{|c|c|c|c|c|c|c|c|c|c|c|c|c|c|}
\hline \multirow[t]{2}{*}{ Study Name } & \multirow[t]{2}{*}{$\begin{array}{l}\text { Fluid } \\
\text { type }\end{array}$} & \multicolumn{2}{|l|}{ Age (years) } & \multicolumn{2}{|c|}{ Gender } & \multirow[t]{2}{*}{ CKD } & \multicolumn{2}{|c|}{ Baseline serum creatinine (mg/dl) } & \multirow{2}{*}{$\begin{array}{l}\text { Sepsis } \\
\text { and/or } \\
\text { septic } \\
\text { shock }\end{array}$} & \multirow[t]{2}{*}{ MV } & \multirow[t]{2}{*}{ Vasopressor } & \multicolumn{2}{|c|}{$\begin{array}{l}\text { ICU admission } \\
\text { indication }\end{array}$} \\
\hline & & Mean (SD) & $\begin{array}{l}\text { Median } \\
\text { (IQR) }\end{array}$ & Male & Female & & Mean & Median & & & & Medical & Surgical \\
\hline \multirow[t]{2}{*}{ Young [10] } & Balanced & $\begin{array}{l}60.1 \\
(16.79)\end{array}$ & - & $64 \%$ & $36 \%$ & - & $\begin{array}{l}0.98 \\
(0.76)\end{array}$ & & $4 \%$ & $67 \%$ & - & $29 \%$ & $71 \%$ \\
\hline & Saline & $\begin{array}{l}60.95 \\
(16.25)\end{array}$ & & $67 \%$ & $34 \%$ & & $\begin{array}{l}0.99 \\
(0.68)\end{array}$ & & $4 \%$ & $66 \%$ & & $28 \%$ & $72 \%$ \\
\hline \multirow[t]{2}{*}{ Verma [16] } & Balanced & - & $\begin{array}{l}62 \\
(45-70)\end{array}$ & $62 \%$ & $38 \%$ & - & - & $\begin{array}{l}0.85 \\
(0.58-1.34)\end{array}$ & $46 \%$ & $58 \%$ & $46 \%$ & $58 \%$ & $42 \%$ \\
\hline & Saline & & $\begin{array}{l}64 \\
(46-72)\end{array}$ & $64 \%$ & $36 \%$ & & & $0.9(0.6-1.21)$ & $41 \%$ & $56 \%$ & $32 \%$ & $48 \%$ & $52 \%$ \\
\hline \multirow[t]{2}{*}{ Semler [15] } & Balanced & - & $\begin{array}{l}58 \\
(44-69)\end{array}$ & $57 \%$ & $43 \%$ & $17 \%$ & - & $0.89(0.47-1.1)$ & $15 \%$ & $34 \%$ & $26 \%$ & $78 \%$ & $22 \%$ \\
\hline & Saline & & $\begin{array}{l}58 \\
(44-69)\end{array}$ & $58 \%$ & $42 \%$ & $17 \%$ & & $0.89(0.47-1.1)$ & $15 \%$ & $35 \%$ & $26 \%$ & $79 \%$ & $21 \%$ \\
\hline \multirow[t]{2}{*}{ Semler [11] } & Balanced & - & $\begin{array}{l}57 \\
(44-68)\end{array}$ & $52 \%$ & $48 \%$ & $23 \%$ & - & - & $25 \%$ & $34 \%$ & $22 \%$ & - & - \\
\hline & Saline & & $\begin{array}{l}58 \\
(46-70)\end{array}$ & $54 \%$ & $46 \%$ & $23 \%$ & & & $29 \%$ & $34 \%$ & $25 \%$ & & \\
\hline \multirow[t]{2}{*}{ Young [17] } & Balanced & $38(19)$ & - & $73 \%$ & $27 \%$ & - & - & - & - & - & - & - & - \\
\hline & Saline & $39(14)$ & & $79 \%$ & $21 \%$ & & & & & & & & \\
\hline \multirow{2}{*}{$\begin{array}{l}\text { Ratanarat } \\
{[18]}\end{array}$} & Balanced & - & - & - & - & - & - & - & - & - & - & - & - \\
\hline & Saline & & & & & & & & & & & & \\
\hline
\end{tabular}

CKD chronic kidney disease, $M V$ mechanical ventilator, ICU intensive care unit, $S D$ standard deviation, IQR interquartile range

in this study as composite outcome of death, persistent kidney dysfunction, and/or new RRT in comparison to isotonic fluids which is contrast to our analysis, but there was no difference between both fluid groups in each of the components of the primary outcome which included in-hospital mortality at 30 days, receipt of new RRT, and a final creatinine level more than $200 \%$ from baseline. As well, there was no difference in developing stage two or more kidney injury between both groups [15].

Our results are against the before and after treatment study in which Yunos et al. showed decreased incidence of AKI and new RRT when chloride liberal fluids were replaced by chloride restrictive fluids [20]. This study has several limitations that decreased the strength and the significance of its findings including that interventions were not randomized, and other fluid types were given during each study periods.

Furthermore, other studies did not show any difference in outcomes with the use of balanced crystalloid fluid solutions in comparison to normal saline. In two RCTs, there were no differences in AKI and in-hospital mortality when balanced fluids are compared to isotonic saline in heterogeneous ICU population [10, 11]. As well, these findings were evident in a retrospective study in non-surgical sepsis patients [5].

On the other hand, many retrospective studies showed improved outcomes when balanced crystalloids are compared to isotonic saline. Balanced fluids were associated

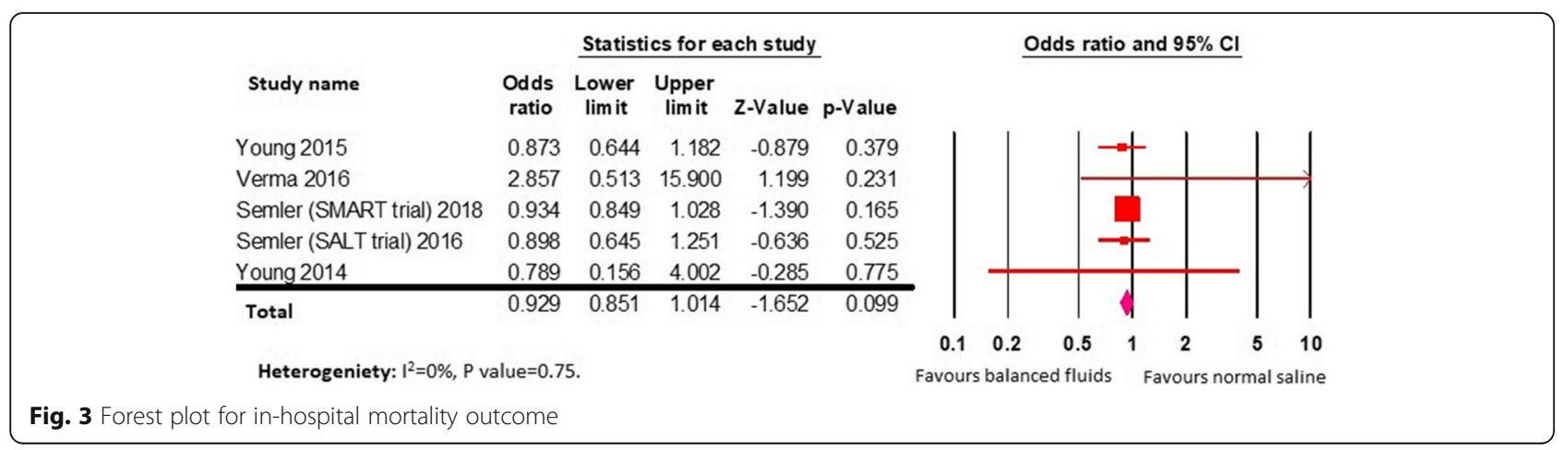




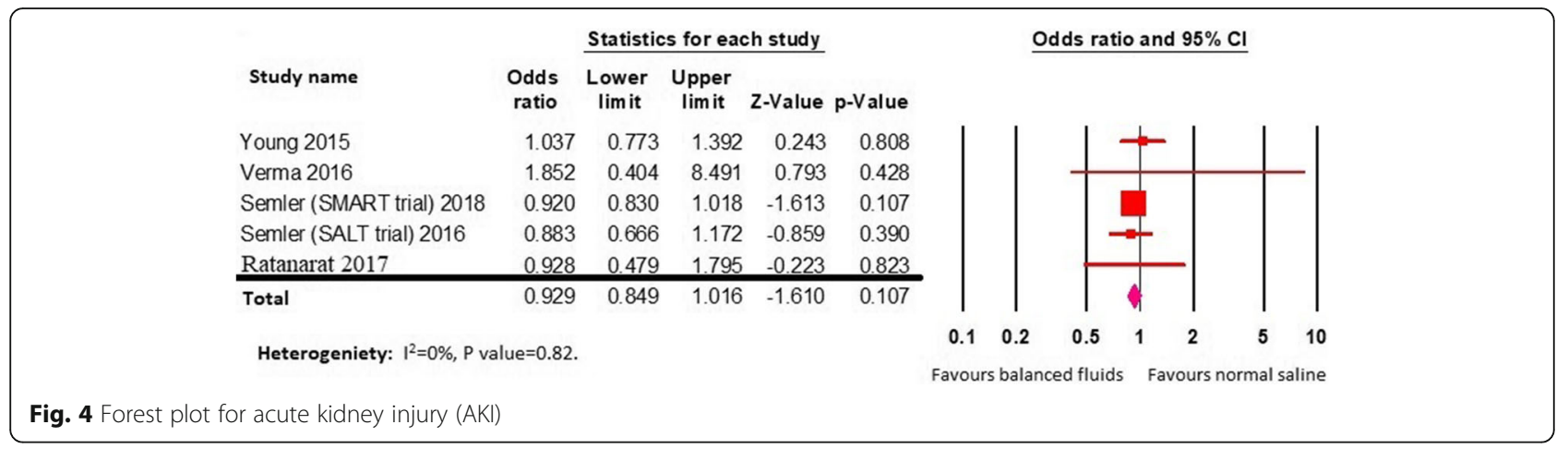

with reduced in-hospital mortality and incidence of AKI in two retrospective analysis of large number of critically ill patients but both analyses have significant confounding variable that might have led to biases [21, 22].

This meta-analysis has proven that there is no difference between balanced crystalloids and isotonic saline solutions on the incidence of AKI, in-hospital mortality, overall ICU mortality, or new RRT in critically ill patients. The results of ongoing clinical trials are investigating the outcomes associated with different fluid types and will determine future recommendations in adjunct with this meta-analysis [23, 24].

\section{Limitations}

Our meta-analysis has several limitations. First, some studies were of limited quality given the small sample size in comparison to other studies. Second, the patients in each study arm still could have received the other fluid type either before enrollment especially in the operation rooms or in the emergency department or during the study and this factor could alter our analysis findings. Third, the included studies have different designs and only three studies are double-blinded randomized controlled trials. Fourth, follow-up period was variable between studies as outlined in Table 1. Fifth, sensitivity analysis was not done since studies did not provide data about specific clinical situations like septic shock. Furthermore, we are limited by the fact that the results of meta-analysis were affected by one large randomized trial. Finally, study fluid administration was given only in first 24 and $72 \mathrm{~h}$ in two studies after randomization.

\section{Conclusion}

There is no significant difference between balanced crystalloids and isotonic saline in the incidence of in-hospital mortality, AKI, ICU mortality, or need for new RRT in critically ill patients. Further powerful studies are required to determine the relationship between two fluid groups and various clinical outcomes.

\section{Additional files}

Additional file 1: Figure S1. Forest plot of intensive care unit (ICU) mortality. (JPG $72 \mathrm{~kb}$ )

Additional file 2: Figure S2. Forest Plot for new renal replacement therapy. (JPG $92 \mathrm{~kb}$ )

\section{Abbreviations}

AKI: Acute kidney injury; Cl: Confidence interval; ICU: Intensive care unit; OR: Odds ratio; P: P value; RCT: Randomized clinical trial; RRT: Renal replacement therapy

\section{Acknowledgements}

The work team would like to thank Katherine Negele, research assistant, and Jennifer Godlesky, library manager at Hurley Medical Center, for language revision of this manuscript.

\section{Availability of data and materials}

We declare that all data and material involved in this research are available on request.

\section{Authors' contributions}

$A A, M B, M B$, and $Y Z$ contributed to the literature search. $A A, M B, M B$, and $Y Z$ contributed to the data extraction. $\mathrm{KH}$ and $Y Z$ contributed to the data analysis. $Y Z, L R, M B$, and $K H$ contributed to the manuscript drafting. GB and $Y Z$ contributed to the manuscript revision and final approval. All authors read and approved the final manuscript.

Ethics approval and consent to participate

Not applicable.

\section{Consent for publication}

I am the corresponding author (Yazan Zayed) and on behalf of all authors, I consent for the publication of this paper at the Journal of Intensive Care.

\section{Competing interests}

The authors declare that they have no competing interests.

\section{Publisher's Note}

Springer Nature remains neutral with regard to jurisdictional claims in published maps and institutional affiliations.

\section{Author details}

${ }^{1}$ Internal Medicine Department, Hurley Medical Center/Michigan State University College of Human Medicine, Flint, MI, USA. ${ }^{2}$ Internal Medicine Department, University of Toledo College of Medicine and Life Sciences, Toledo, OH, USA. ${ }^{3}$ East Lansing, USA. 
Received: 1 June 2018 Accepted: 7 August 2018

Published online: 17 August 2018

\section{References}

1. Dellinger RP, Levy MM, Rhodes A, Annane D, Gerlach H, Opal SM, et al. Surviving sepsis campaign: international guidelines for management of severe sepsis and septic shock, 2012. Intensive Care Med. 2013;39:165-228. Available from: http://www.ncbi.nlm.nih.gov/pubmed/23361625

2. Myburgh JA, Mythen MG. Resuscitation fluids. N Engl J Med. 2013;369:2462-3. Available from: http:/www.ncbi.nIm.nih.gov/pubmed/24350966

3. Yunos NM, Bellomo R, Hegarty C, Story D, Ho L, Bailey M. Association between a chloride-liberal vs chloride-restrictive intravenous fluid administration strategy and kidney injury in critically ill adults. JAMA. 2012;308:1566-72. Available from: http://www.ncbi.nlm.nih.gov/pubmed/23073953

4. Hammond NE, Taylor C, Finfer S, Machado FR, An Y, Billot L, et al. Patterns of intravenous fluid resuscitation use in adult intensive care patients between 2007 and 2014: an international cross-sectional study. PLoS One. 2017;12: e0176292. Available from: http://www.ncbi.nlm.nih.gov/pubmed/28498856

5. Raghunathan K, Shaw A, Nathanson B, Stürmer T, Brookhart A, Stefan MS, et al. Association between the choice of IV crystalloid and in-hospital mortality among critically ill adults with sepsis*. Crit Care Med. 2014;42: 1585-91. Available from: http://www.ncbi.nlm.nih.gov/pubmed/24674927

6. Soni N. British Consensus Guidelines on Intravenous Fluid Therapy for Adult Surgical Patients (GIFTASUP): Cassandra's view. Anaesthesia. 2009;64:235-8. Available from: http://www.ncbi.nlm.nih.gov/pubmed/19302633

7. Chua H-R, Venkatesh B, Stachowski E, Schneider AG, Perkins K, Ladanyi $\mathrm{S}$, et al. Plasma-Lyte 148 vs $0.9 \%$ saline for fluid resuscitation in diabetic ketoacidosis. J Crit Care. 2012;27:138-45. Available from: http://www. ncbi.nlm.nih.gov/pubmed/22440386

8. Shaw AD, Bagshaw SM, Goldstein SL, Scherer LA, Duan M, Schermer CR, et al. Major complications, mortality, and resource utilization after open abdominal surgery: 0.9\% saline compared to Plasma-Lyte. Ann Surg. 2012; 255:821-9. Available from: http://www.ncbi.nlm.nih.gov/pubmed/22470070

9. Shaw AD, Raghunathan K, Peyerl FW, Munson SH, Paluszkiewicz SM, Schermer CR. Association between intravenous chloride load during resuscitation and inhospital mortality among patients with SIRS. Intensive Care Med. 2014;40: 1897-905. Available from: http://www.ncbi.nlm.nih.gov/pubmed/25293535

10. Young P, Bailey M, Beasley R, Henderson S, Mackle D, McArthur C, et al. Effect of a buffered crystalloid solution vs saline on acute kidney injury among patients in the intensive care unit: the SPLIT randomized clinical trial. JAMA. 2015;314:1701-10. Available from: http://www.ncbi.nlm.nih.gov/pubmed/26444692

11. Semler MW, Wanderer JP, Ehrenfeld JM, Stollings JL, Self WH, Siew ED, et al. Balanced crystalloids versus saline in the intensive care unit. The SALT randomized trial. Am J Respir Crit Care Med. 2017;195:1362-72. Available from: http://www.ncbi.nlm.nih.gov/pubmed/27749094

12. Huang $L$, Zhou X, Yu H. Balanced crystalloids vs $0.9 \%$ saline for adult patients undergoing non-renal surgery: a meta-analysis. Int J Surg. 2018;51:1-9. Available from: http://www.ncbi.nIm.nih.gov/pubmed/29339230

13. Serpa Neto A, Martin Loeches I, Klanderman RB, Freitas Silva R, Gama de Abreu M, Pelosi P, et al. Balanced versus isotonic saline resuscitation-a systematic review and meta-analysis of randomized controlled trials in operation rooms and intensive care units. Ann Transl Med. 2017;5:323. Available from: http://www.ncbi.nlm.nih.gov/pubmed/28861420

14. Moher D, Shamseer L, Clarke M, Ghersi D, Liberati A, Petticrew M, et al. Preferred reporting items for systematic review and meta-analysis protocols (PRISMA-P) 2015 statement. Syst Rev. 2015;4:1. Available from: http://www.ncbi.nlm.nih.gov/pubmed/25554246

15. Semler MW, Self WH, Wanderer JP, Ehrenfeld JM, Wang L, Byrne DW, et al. Balanced crystalloids versus saline in critically ill adults. N Engl J Med. 2018; 378:829-39. Available from: http://www.ncbi.nlm.nih.gov/pubmed/29485925

16. Verma B, Luethi N, Cioccari L, Lloyd-Donald P, Crisman M, Eastwood G, et al. A multicentre randomised controlled pilot study of fluid resuscitation with saline or Plasma-Lyte 148 in critically ill patients. Crit Care Resusc. 2016;18: 205-12. Available from: http://www.ncbi.nlm.nih.gov/pubmed/27604335

17. Young JB, Utter GH, Schermer CR, Galante JM, Phan HH, Yang Y, et al, Saline versus Plasma-Lyte $A$ in initial resuscitation of trauma patients: a randomized trial. Ann Surg. 2014;259:255-62. Available from: http:// www.ncbi.nlm.nih.gov/pubmed/23732264
18. Ratanarat R; Sanguanwit, $P$; Chitsomkasem A et al. The effects of normal saline versus balanced crystalloid solution as a resuscitation fluid on acute kidney injury in shock patients: a randomized opened label-controlled trial. 30th Annu Congr Eur Soc intensive care Med ESICM 2017. 2017.

19. Kawano-Dourado L, Zampieri FG, Azevedo LCP, Corrêa TD, Figueiró M, Semler MW, et al. Low- versus high-chloride content intravenous solutions for critically ill and perioperative adult patients: a systematic review and meta-analysis. Anesth Analg. 2018;126:513-21. Available from: http://www. ncbi.nlm.nih.gov/pubmed/29189271

20. Yunos NM, Bellomo R, Glassford N, Sutcliffe H, Lam Q, Bailey M. Chlorideliberal vs. chloride-restrictive intravenous fluid administration and acute kidney injury: an extended analysis. Intensive Care Med. 2015;41:257-64. Available from: http://www.ncbi.n/m.nih.gov/pubmed/25518951

21. Zampieri FG, Ranzani OT, Azevedo LCP, Martins IDS, Kellum JA, Libório $A B$. Lactated ringer is associated with reduced mortality and less acute kidney injury in critically ill patients: a retrospective cohort analysis. Crit Care Med. 2016;44:2163-70. Available from: http://www. ncbi.nlm.nih.gov/pubmed/27495820

22. Raghunathan K, Bonavia A, Nathanson BH, Beadles CA, Shaw AD, Brookhart MA, et al. Association between initial fluid choice and subsequent in-hospital mortality during the resuscitation of adults with septic shock. Anesthesiology. 2015;123:1385-93. Available from: http:// www.ncbi.nlm.nih.gov/pubmed/26414499

23. Zampieri FG, Azevedo LCP, Corrêa TD, Falavigna M, Machado FR, de Assunção MSC, et al. Study protocol for the balanced solution versus saline in intensive care study (BaSICS): a factorial randomised trial. Crit Care Resusc. 2017;19:175-82. Available from: http://www.ncbi.nlm.nih.gov/pubmed/28651514

24. Hammond NE, Bellomo R, Gallagher M, Gattas D, Glass P, Mackle D, et al. The Plasma-Lyte 148 v Saline (PLUS) study protocol: a multicentre, randomised controlled trial of the effect of intensive care fluid therapy on mortality. Crit Care Resusc. 2017;19:239-46. Available from: http://www.ncbi. nlm.nih.gov/pubmed/28866974

\section{Ready to submit your research? Choose BMC and benefit from:}

- fast, convenient online submission

- thorough peer review by experienced researchers in your field

- rapid publication on acceptance

- support for research data, including large and complex data types

- gold Open Access which fosters wider collaboration and increased citations

- maximum visibility for your research: over $100 \mathrm{M}$ website views per year

At BMC, research is always in progress.

Learn more biomedcentral.com/submissions 